\title{
Outer Membrane Vesicle Induction and Isolation for Vaccine Development
}

\author{
Melanie D. Balhuizen, Edwin J. A. Veldhuizen* and Henk P. Haagsman \\ Division of Infectious Diseases and Immunology, Department of Biomolecular Health Sciences, Faculty of Veterinary \\ Medicine, Utrecht University, Utrecht, Netherlands
}

OPEN ACCESS

Edited by:

Mickaël Desvaux,

Institut National de la Recherche

Agronomique (INRA), France

Reviewed by:

Mariagrazia Pizza,

GlaxoSmithKline, Italy

Denice C. Bay,

University of Manitoba, Canada

Maricarmen Rojas Lopez,

GlaxoSmithKline, Italy

Roland Lloubes,

UMR7255 Laboratoire d'ingénierie

des systèmes macromoléculaires

(LISM), France

${ }^{*}$ Correspondence: Edwin J. A. Veldhuizen

e.j.a.veldhuizen@uu.nl

Specialty section:

This article was submitted to Microbial Physiology and Metabolism, a section of the journal

Frontiers in Microbiology

Received: 13 November 2020

Accepted: 08 January 2021

Published: 04 February 2021

Citation:

Balhuizen MD, Veldhuizen EJA and

Haagsman HP (2021) Outer

Membrane Vesicle Induction and Isolation for Vaccine Development.

Front. Microbiol. 12:629090.

doi: 10.3389/fmicb.2021.629090
Gram-negative bacteria release vesicular structures from their outer membrane, so called outer membrane vesicles (OMVs). OMVs have a variety of functions such as waste disposal, communication, and antigen or toxin delivery. These vesicles are the promising structures for vaccine development since OMVs carry many surface antigens that are identical to the bacterial surface. However, isolation is often difficult and results in low yields. Several methods to enhance OMV yield exist, but these do affect the resulting OMVs. In this review, our current knowledge about OMVs will be presented. Different methods to induce OMVs will be reviewed and their advantages and disadvantages will be discussed. The effects of the induction and isolation methods used in several immunological studies on OMVs will be compared. Finally, the challenges for OMV-based vaccine development will be examined and one example of a successful OMV-based vaccine will be presented.

Keywords: outer membrane vesicles, isolation, induction, vaccine development, Bordetella pertussis, Neisseria meningitidis, host defense peptides

\section{INTRODUCTION ON OUTER MEMBRANE VESICLES}

Gram-negative bacteria have two membranes, the inner membrane (IM) and the outer membrane $(\mathrm{OM})$ with a network of peptidoglycan (PG) and the periplasmic space in between. Both the IM and OM consist of phospholipids and membrane proteins, with only the outer leaflet of the OM containing lipopolysaccharide (LPS). From the OM, small protrusions can form that pinch off and become extracellular vesicles, called outer membrane vesicles (OMVs; Figure 1; Beveridge, 1999). Resulting OMVs are between 20 and $300 \mathrm{~nm}$ in diameter. They consist of a single lipid bilayer containing LPS, phospholipids, and various outer membrane proteins (OMPs), which represents the OM of the originating bacteria. Formation of OMVs has been the subject of much debate, since the driving force of OMV formation was long unknown (Zhou et al., 1998; Haurat et al., 2011). The formation of OMVs was long thought to be an arbitrary stress response from bacterial cells (McBroom and Kuehn, 2007), but OMVs were later proven to have many more functions, which will be discussed below.

\section{Formation of OMVs}

For OMV formation, it is necessary to detach the OM from the PG layer and the IM. These layers are stably linked by many different lipoproteins. A local decrease in the number of 


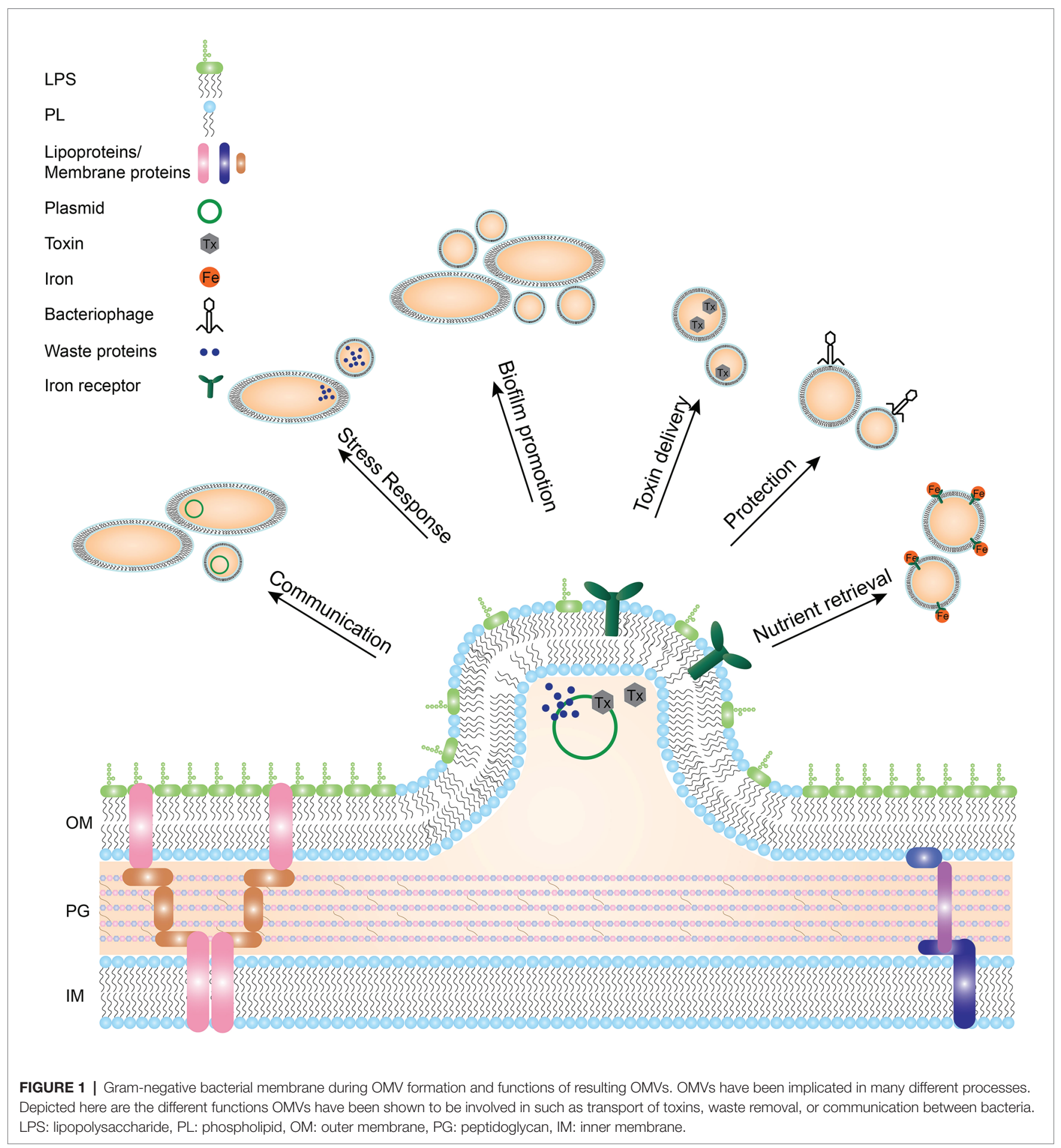

lipoproteins, and therefore the number of crosslinks, has been implicated in OMV formation. For example, the deletion of lipoprotein (Lpp) in combination with magnesium starvation or the deletion of outer membrane protein $\mathrm{A}(\mathrm{OmpA})$ in Escherichia coli that results in hypervesiculating mutants (Sonntag et al., 1978; Yem and Wu, 1978). Similarly, the Tol-Pal system consists of several proteins connecting the IM with the OM and disruption of the Tol-Pal system resulted in hypervesiculation in Salmonella and E. coli (Bernadac et al., 1998; Deatherage et al., 2009). Furthermore, alterations to the PG structure can prevent proper attachment of lipoproteins, which in turn decreases the number of crosslinks between the IM and OM. This indirectly causes an increase in OMV formation due to outer-membrane instability. For instance, a PG hydrolase mutant of E. coli, defective in peptide crosslinks of the PG, prevented attachment of Lpp in the PG layer (Schwechheimer et al., 2014). 
An increase in membrane turgor, the force of internal fluids pressing outward, also results in an increase in OMV release. For example, the accumulation of misfolded periplasmic proteins in a periplasmic serine endoprotease $(\operatorname{deg} P)$ mutant, resulting in loss of a periplasmic chaperone, resulted in hypervesiculation (Schwechheimer and Kuehn, 2013). In a mutant defective in PG recycling, PG fragments accumulated and increased membrane turgor, leading to membrane pressure and increased OMV release. It was shown that Lpp-based crosslinks between the PG and IM in this mutant remained at a similar level as in the wild-type strain (Schwechheimer et al., 2014). This suggests that this mechanism is independent of crosslink formation and therefore increases OMV formation through a distinct mechanism (Schwechheimer and Kuehn, 2013; Schwechheimer et al., 2014).

The most recent hypothesis for OMV formation is the induction of curvature in the $\mathrm{OM}$ due to an increase in phospholipid (PL) content. An increase in OMV formation was shown for mutants missing components of a retrograde PL transporter system (Roier et al., 2016). This was shown for Haemophilus influenzae, Vibrio cholerae, and E. coli, indicating that it is a conserved mechanism in several species. Altogether, many different mechanisms for OMV formation have been described in the past decades and most likely all these mechanisms are simultaneously at play in bacteria (McBroom et al., 2006; Kulp and Kuehn, 2010; Kulkarni and Jagannadham, 2014; Schwechheimer and Kuehn, 2015).

\section{Functions of OMVs}

OMVs exert many different functions, all beneficial to the bacterium. Mostly, OMVs act as a transportation system not only for proteins, but also for DNA and RNA (Dorward et al., 1989; Koeppen et al., 2016; Bitto et al., 2017). Vesicles provide a protected environment for bacterial molecules and delivery by OMVs may act as a long-distance delivery system (Bomberger et al., 2009; Jones et al., 2020). Additionally, transport by OMVs prevents dilution of cargo. OMV cargo has been shown to be involved in inter-cellular communication. For example, OMVs of Pseudomonas aeruginosa contain the Pseudomonas quinolone signal (PQS) and removal of OMVs from the bacterial culture inhibits cell-cell communication (Mashburn and Whiteley, 2005). Furthermore, antibiotic resistance genes are often transported via OMVs. OMVs from Neisseria gonorrhoeae were shown to contain circular DNA and supplementation with these OMVs provided penicillin resistance in susceptible bacterial strains (Dorward et al., 1989). Additionally, Acinetobacter baumannii was shown to transfer carbapenem resistance genes in their OMVs (Rumbo et al., 2011). However, OMVs are not only used for communication within one bacterial species, but also for inter-species communication. When E. coli or Salmonella species were incubated with OMVs derived from $P$. aeruginosa or Shigella flexneri, antigens of the latter two were readily detected on the surface of the first two bacterial species, suggesting interspecies communication by OMVs (Kadurugamuwat and Beveridge, 1999). Furthermore, E. coli OMVs were shown to package Shiga toxins (Kolling and Matthews, 1999) and P. aeruginosa OMVs were shown to contain PG hydrolases and fuse with E. coli and
Staphylococcus aureus membranes, thereby eradicating competing bacterial species (Kadurugamuwa and Beveridge, 1996).

Besides bacterial interactions, OMVs are involved in pathogen-host interactions (Jones et al., 2020; Zingl et al., 2020). OMVs are used by many bacterial species to deliver toxins and other virulence factors (Kadurugamuwa and Beveridge, 1995; Ellis and Kuehn, 2010; Yoon, 2016; Gasperini et al., 2017; Jha et al., 2017). For example, P. aeruginosa was shown to package small RNAs in OMVs that silenced host RNA involved in the innate immune response (Koeppen et al., 2016). Sorting of OMV cargo must therefore be a selective process and might be regulated by LPS microdomains, but the exact sorting mechanism has yet to be elucidated (Haurat et al., 2011; Bonnington and Kuehn, 2014).

Furthermore, OMVs are beneficial to bacterial growth in several ways. Despite the fact that OMV release seems to be a one-way process, OMVs also have been shown to fuse with bacterial membranes, for instance to aid in nutrient acquisition. For Neisseria meningitidis, it was shown that OMVs are enriched in proteins involved in iron and zinc acquisition (Lappann et al., 2013). Similarly, for Bordetella pertussis, the process of iron retrieval by OMVs from medium was demonstrated. When OMVs from an iron-rich culture were supplemented to a culture growing in iron-limited conditions, they were able to transfer iron to bacterial cells and boost bacterial growth (Gasperini et al., 2017).

Another function related to OMV production is protection, both from exogenous and endogenous molecules. For instance, OMVs are used to dispose of bacterial waste, such as misfolded proteins, to prevent bacteria from collapsing under the pressure (Manning and Kuehn, 2013; Schwechheimer et al., 2013). This is regulated by stress responses, such as the sigma E pathway (Kulp and Kuehn, 2010) or independent of envelope stress responses (McBroom and Kuehn, 2007), as a protection mechanism. Many exogenous molecules can also threaten bacteria such as antimicrobial peptides (AMPs) and bacteriophages. Addition of OMVs to an E. coli or Helicobacter pylori culture increased bacterial resistance to AMPs and bacteriophages (Manning and Kuehn, 2011; Roszkowiak et al., 2019; Murray et al., 2020), presumably by acting as a decoy for these substances to attach to, instead of targeting the bacterial membrane.

The functions of OMVs in biofilms have been described in all stages of biofilm formation, being a common component of the biofilm matrix (Schooling and Beveridge, 2006). Addition of OMVs to $H$. pylori cultures was shown to correlate with increased biofilm forming ability (Yonezawa et al., 2009). OMVs of $P$. aeruginosa have been shown to aid in attachment and aggregation of bacterial cells in early stages of biofilm formation and carry molecules to protect the biofilm later on such as $\beta$-lactamases (Ciofu, 2000). The most well-known functions of OMVs are schematically depicted in Figure $\mathbf{1}$.

Despite the many physiological functions of OMV, their release is often insignificant and insufficient for industrial purposes (van der Pol et al., 2015). Several methods exist to induce OMV release in bacterial cultures and increase OMV yields (Klimentová and Stulík, 2015). However, these induced 
OMVs may have different properties compared to OMVs that are spontaneously released from bacteria (Collins, 2011; Schwechheimer and Kuehn, 2013; Michel et al., 2020; Balhuizen et al., 2021). In this review, we describe the different methods used to induce OMVs and to compare the properties of the resulting vesicles. Additionally, a standard nomenclature is introduced to prevent confusion between different types of OMVs. The potential of OMV-based vaccines is illustrated using $N$. meningitidis as an example, since it is the only licensed OMV-based vaccine to date. Furthermore, we compared immunological properties of differently induced OMVs from B. pertussis, a pathogen for which an OMV-based vaccine exhibits great potential. Future challenges for OMV-based vaccines are discussed, as well as different applications for use of OMVs.

\section{INDUCTION AND ISOLATION OF OMVs FOR THERAPEUTIC PURPOSES}

OMVs have many potential therapeutic applications, which will be described later, but often their release is insignificant, resulting in low harvested yields from bacterial cultures. Spontaneous OMVs (sOMVs) are naturally released by Gramnegative bacteria and considered most similar to OMVs formed in vivo based on protein and lipid content (Gasperini et al., 2017, 2018; Valguarnera and Feldman, 2017). These OMVs can be obtained by growing bacteria until end-logarithmic phase and harvested without the addition of any foreign molecules. Therefore, all OMVs have been formed spontaneously and resemble the composition of in vivo formed OMVs by unstressed bacteria. The low yield of sOMVs makes them not easily feasible for vaccine production, yet these vesicles are most desirable for vaccine development due to their natural composition resembling the outer membrane of the bacterium.

\section{Induction Methods of OMVs}

Several methods exist to increase release of OMVs, all with their own advantages and disadvantages (Figure 2). For instance, vesicles can be induced by disruption of the membrane with either addition of a detergent or by sonication. OMVs can also be induced by an extracting agent, such as ethylenediaminetetraacetic acid (EDTA), or with sub-lethal concentrations of antibiotics (Maredia et al., 2012; Duperthuy et al., 2013). Furthermore, OMVs might also be induced by genetic modifications, which will be discussed in more detail below. These different methods can all distinctly affect the resulting OMVs in size, proteolytic or thermal stability, or composition, which may influence the immune responses evoked by the OMVs (Collins, 2011).

In the next paragraphs, different methods to induce OMVs will be discussed in more detail, starting with genetic modifications that are applied to increase yields of OMVs (gOMVs; Ojima et al., 2020). Included in the term gOMVs are generalized modules for membrane antigens (GMMA), since this term likewise refers to OMVs from bacteria in which mutations induce hypervesiculation (Gerke et al., 2015). These gOMVs can be produced by various mutations, for example, by deletion of the tolR gene, which is part of the Tol-Pal system discussed above (Micoli et al., 2020). The Tol-Pal system has often been a target for creation of hypervesiculating mutants (Henry et al., 2004; Chen et al., 2016; Stevenson et al., 2018). Deletion of lipoproteins connecting the $\mathrm{OM}$ and the PG layer, such as Lpp for E. coli, has been shown to increase OMV production (Sonntag et al., 1978). Another example is the knock-out of chaperones to increase stress due to the presence of misfolded proteins, which in turn increases vesicle formation, as shown for a $\operatorname{deg} P$ mutant of E. coli (McBroom et al., 2006). Deletion of a lytic transglycosylase, which resulted in hypervesiculating $N$. meningitidis strain, is another example of a long list of deletion mutants (Adu-Bobie et al., 2004; Ferrari et al., 2006). Deletion of genes is not the only modification that resulted in hypervesiculating bacteria. For example, overexpression of the outer membrane protease OmpT resulted in hypervesiculation in E. coli (Premjani et al., 2014). Additionally, expression of the deacylase PagL resulted in hypervesiculation, due to increased curvature of the bacterial outer membrane, caused by an inverted cone-shaped LPS (Elhenawy et al., 2016). This list is not exhaustive and research is still performed to identify additional hypervesiculating mutations. These modifications result in spontaneously formed vesicles, but a disadvantage is that these gOMVs can differ from in vivo formed vesicles since the bacterium has been genetically altered. For example, cargo in gOMVs resulting from a $\operatorname{deg} P$ mutant is substantially different from cargo in sOMVs, with an increased presence of periplasmic proteins, which are suggested to be misfolded (Schwechheimer and Kuehn, 2013). Analysis of gOMVs produced by a $\Delta$ tolB mutant in Buttiauxella agrestis even revealed multilamellar vesicles (Takaki et al., 2020) and E. coli $\Delta$ tolR gOMVs were shown to have reduced entry into epithelial Caco-2 cells (Pérez-Cruz et al., 2016). Another disadvantage of genetic modification is that one mutation may not work in all Gram-negative bacteria, requiring research to find distinct mutations for different bacteria. To facilitate this, publishing data on genetic mutations not resulting in hypervesiculating bacterial strains would prevent other research groups from trying similar strategies.

A second method, using detergent for the extraction of OMVs (dOMVs), has been used for decades and is a widespread method in industry. Neisseria meningitidis OMV vaccines used to be prepared based on detergent extraction (Acevedo et al., 2014). With this method OMVs are induced with detergent-like molecules such as deoxycholate or sodium dodecyl sulfate. These molecules interact with the bacterial membrane to increase vesicle formation and additionally remove LPS from the outer membrane, creating LPS-containing micelles. The resulting dOMVs lack LPS (van der Pol et al., 2015), which will decrease the undesired LPS-based innate immune response. However, the loss of LPS results in loss of many antigens, which are loosely attached to the membrane. Additionally, the intrinsic adjuvant activity of OMVs is likewise lost upon LPS removal (van der Pol et al., 2015). This shows that there is a fine balance between potential beneficial and detrimental effects of LPS in OMVs.

Furthermore, OMVs can be induced by membrane destabilization using sonication, which does not remove LPS 


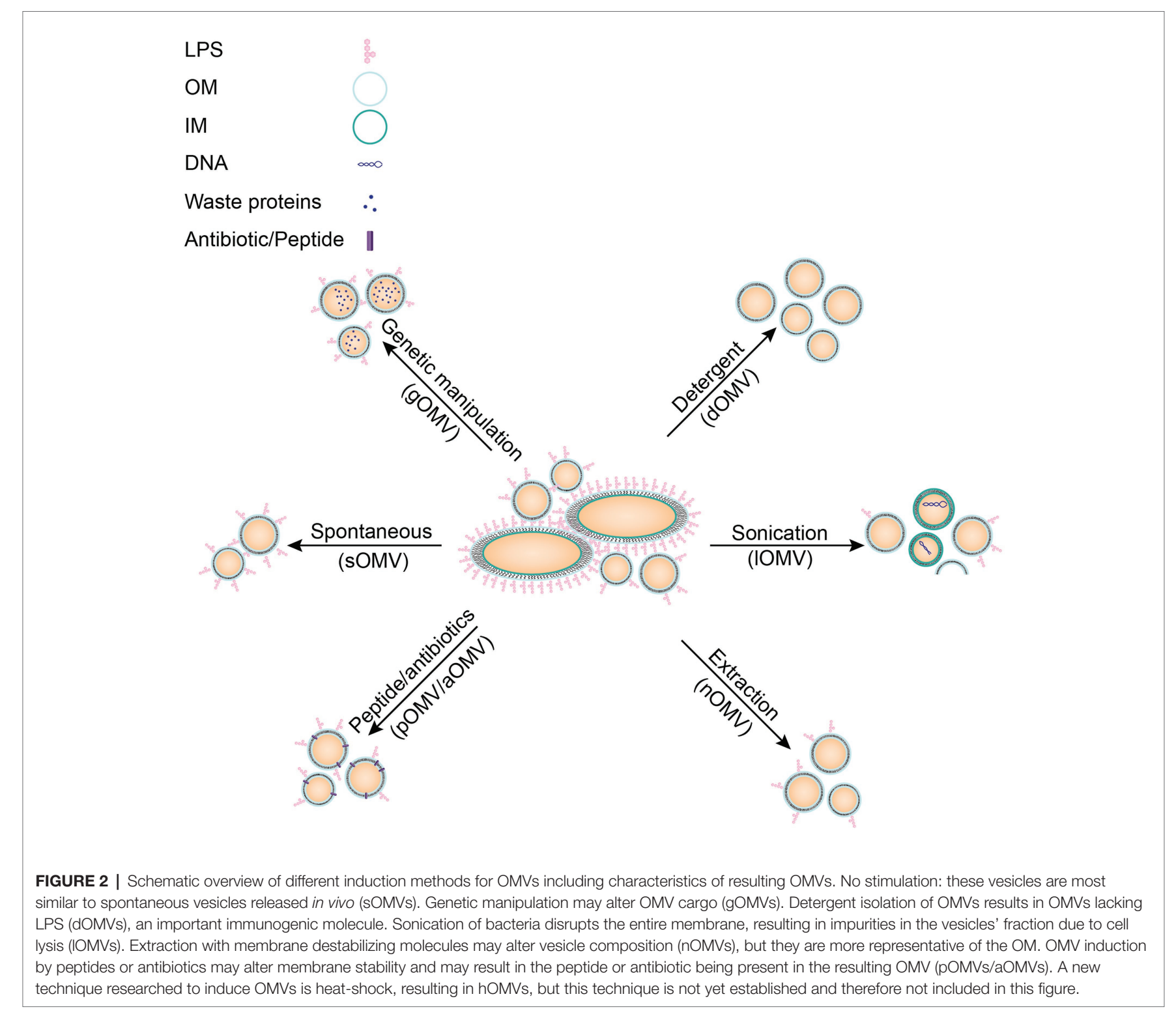

from the membrane (Roberts et al., 2008; Asensio et al., 2011; Bottero et al., 2018). These vesicles are prepared by sonication of the bacterial pellet, thereby forming membrane fragments, which fuse to form lysis OMVs (lOMVs). These lOMVs are not prepared from the bacterial supernatant, where the sOMVs can be found, and therefore likely contain cargo not natively present in OMVs (Roberts et al., 2008). So, despite high OMV yields obtained through sonication of bacteria, these vesicles do not represent in vivo protein compositions of sOMVs and therefore are not always suitable for vaccine development.

Another method to induce OMVs is the use of extraction molecules such as EDTA (van de Waterbeemd et al., 2010). These extraction molecules aim to destabilize the bacterial membrane similar to the two methods described above (dOMVs and lOMVs) but are relatively mild and thus retain LPS and native cargo in the OMVs (van de Waterbeemd et al., 2013a). Therefore, they are named native OMVs (nOMVs).
One such a molecule is EDTA, which is a chelating agent that removes calcium ions from the environment (Hart, 2000). Calcium ions stabilize bacterial membranes by neutralization of repelling negative charges of LPS and other anionic lipids (Thomas and Rice, 2014). Removal of calcium ions causes the negative charges of LPS to repel each other, and thereby it destabilizes the membrane (Clifton et al., 2015). Therefore, yields of OMVs are increased using EDTA, but LPS remains present. These vesicles are better suited for vaccine development but might be less stable due to the lack of calcium ions.

Yet another method to increase OMV release is the induction of membrane stress by supplementation of external molecules, as was shown for naturally occurring antimicrobial peptides (AMPs; Manning and Kuehn, 2011; Balhuizen et al., 2021). These OMVs have been named peptide induced OMVs (pOMVs). AMPs are part of the innate immune system and are expressed by different cell types, such as granulocytes or 
epithelial cells, in response to bacterial signals, such as LPS, or cytokines, such as interleukin 1-beta (IL-1 $\beta$; Zasloff, 2002; van Harten et al., 2018; Mookherjee et al., 2020; Scheenstra et al., 2020). These AMPs often have high affinity for bacterial membranes, which is part of their antibacterial mechanism of action (Zanetti, 2004; Hazlett and Wu, 2011; Schneider et al., 2016, 2017). As discussed above, increased OMV production may be a means of the bacterium to protect from induced stress. Bordetella bronchiseptica pOMVs resulting from induction by the porcine myeloid antimicrobial peptide 36 (PMAP-36) were indeed shown to contain PMAP-36 (Balhuizen et al., 2021). Furthermore, pOMVs contained relatively more phosphatidylglycerol compared to sOMVs, a negatively charged lipid, which might interact with the positively charged AMP. Bordetella bronchiseptica pOMVs were also shown to have decreased thermal stability compared to sOMVs, possibly due to the presence of PMAP-36 in the membrane (Balhuizen et al., 2021). As for peptide-based antibiotics, such as polymyxin B, also these molecules were shown to induce OMV release (Kulkarni et al., 2015). The mechanism of OMV induction might be similar to AMPs mechanism and is based on membrane disruption resulting in stress for the bacterium and subsequent OMV production.

Antibiotics targeting intracellular processes were also shown to induce OMV release. OMV formation might be a response to antibiotics, since in P. aeruginosa it was shown that antibiotics induce PQS secretion (Bru et al., 2019) and PQS was shown to induce OMV formation (Schertzer and Whiteley, 2012). However, antibiotic-induced OMVs (aOMVs) are mostly characterized based on protein content (Godlewska, 2019), so a good comparison to pOMVs cannot be made yet. aOMVs of extra-intestinal pathogenic E. coli were characterized after induction by gentamicin and particle sizes were not altered (Chan et al., 2017). Remarkably, when the cargo of these aOMVs was assessed using mass-spectrometry, mostly cytoplasmic and periplasmic proteins were enriched, relative to sOMVs. Likely these are misfolded proteins formed after gentamicin's interference with the ribosome machinery. Escherichia coli aOMVs induced by ampicillin were shown to have an increased amount of the OMP Pal, further demonstrating that antibiotics can alter OMV cargo (Michel et al., 2020). In another study, Acinetobacter baumannii, was stimulated with tetracycline, imipenem, and eravacycline, and the resulting OMVs were quantified (Yun et al., 2018; Kesavan et al., 2020). Whereas tetracycline did not induce OMV release, imipenem did induce release of aOMVs, which showed a relative increase in OMPs and proteases (Yun et al., 2018). Eravacycline-induced aOMVs likewise contained not only relatively more OMPs but also resistance-associated proteins such as ATP-binding cassette $(A B C)$ and other transporter proteins (Kesavan et al., 2020). This demonstrates the possible risks of this induction method, as sub-lethal concentrations of antibiotics may result in development of antibiotic resistance.

Since these different methods all result in slightly different vesicles, nomenclature to distinguish between different categories is important. However, the current use of abbreviations in literature is not consistent. Different abbreviations are used in literature for an identical OMV type while, vice versa, one abbreviation is sometimes used for two different OMV types. Different induction methods will result in different OMVs. Therefore, OMVs should be extensively studied before being used in immunization studies. In order to compare results from different studies, a common nomenclature is useful. A suggested nomenclature is summarized in Table $\mathbf{1}$ for all OMV types currently described.

\section{Isolation of Secreted OMVs}

Isolation of OMVs is independent of the induction method used and literature shows very similar procedures with small differences between studies. First, OMVs are separated from bacteria by centrifugation (Klimentová and Stulík, 2015). Next, contaminations are removed by filtration. In literature, the use of both 0.22 and $0.45 \mu \mathrm{m}$ filters have been described, being the first discrepancy between methods. The use of a $0.22 \mu \mathrm{m}$ filter could decrease yields by preventing passage of the larger vesicles, since vesicle sizes range between 20 and $300 \mathrm{~nm}$ (Kulp and Kuehn, 2010; Schwechheimer and Kuehn, 2015). After filtration, OMVs can be concentrated by precipitation or ultrafiltration (Klimentová and Stulík, 2015). Vesicles are eventually collected by ultracentrifugation, ranging from 40,000 up to $175,000 \mathrm{xg}$, depending on the bacterial species studied. Unfortunately, rotor type and centrifugation times are not specified in most papers, although these parameters are critical for yields of OMVs (Kohl et al., 2018). Furthermore, ultracentrifugation alone may leave contaminants still present in the isolated OMV fraction. Sucrose density gradient ultracentrifugation will result in the purest fraction of OMVs and therefore also in the most consistent results between labs (Lee et al., 2016). When isolation methods are not described in detail, results obtained in immunization studies are not relevant for industrial application. To ensure possibilities to replicate experiments, transparency and detailed description of methods is critical. This will aid the scientific community and increase the relevance and comparability of described results, which could eventually accelerate OMV-based therapeutic applications.

TABLE 1 | Summary of used abbreviations for OMVs based on their induction method, as described in the text.

\begin{tabular}{|c|c|c|c|}
\hline Method & Abbreviation & Yield & Remarks \\
\hline No induction & sOMV & Low & - \\
\hline Genetically induced OMVs & gOMV & Variable & $\begin{array}{l}\text { Possible change in } \\
\text { cargo }\end{array}$ \\
\hline Detergent induced OMVs & dOMV & High & $\begin{array}{l}\text { Loss of LPS and } \\
\text { lipoproteins }\end{array}$ \\
\hline Sonication induced OMVs & IOMV & High & Contamination with IM \\
\hline $\begin{array}{l}\text { Extraction molecule } \\
\text { induced OMVs }\end{array}$ & nOMV & High & $\begin{array}{l}\text { Potential loss of } \\
\text { membrane stability }\end{array}$ \\
\hline Peptide induced OMVs & pOMV & Low & $\begin{array}{l}\text { Potential loss of } \\
\text { membrane stability }\end{array}$ \\
\hline Antibiotic induced OMVs & aOMV & Variable & $\begin{array}{l}\text { Antibiotic presence or } \\
\text { resistance }\end{array}$ \\
\hline Heat induced OMVs & hOMV & High & $\begin{array}{l}\text { Possible change in } \\
\text { lipid composition }\end{array}$ \\
\hline
\end{tabular}




\section{Applications of OMVs}

The use of OMVs as a vaccine for their originating bacterium will be elaborated on below, but OMVs have many more therapeutic purposes. For instance, OMVs could also be suitable as a carrier system for proteins, glycans, and other molecules (Gerritzen et al., 2017; Gnopo et al., 2017). OMVs may be decorated with proteins, for instance, by coupling heterologous antigens to endogenous autotransporters in a hypervesiculating bacterial strain. This technique is developed for the hemoglobinbinding protease ( $\mathrm{Hbp}$ ) of $E$. coli in a hypervesiculating Salmonella enterica serovar typhimurium SL3261, using not only genetic engineering but also click chemistry to ensure display of larger antigens (Jong et al., 2014; van Ulsen et al., 2018). This technique can provide a robust system using welldefined OMVs as carrier that can be decorated with antigens of any bacterium of interest. The principle was demonstrated for antigens of Mycobacterium tuberculosis and Chlamydia trachomatis, where the antigens were shown to be processed and recognized (Daleke-Schermerhorn et al., 2014). Not only can protein antigens be displayed on the OMV surface, but also heterologous glycans can be displayed. Delivery of Salmonella $\mathrm{O}$-antigen by gOMVs induced high levels of IgG antibodies in mice (De Benedetto et al., 2017). Glycosylated OMVs have also been proven to protect against subsequent bacterial challenges and may be another route of immunization with the use of OMVs (Gnopo et al., 2017). Thus, OMVs are useful as carrier system, and they also have useful intrinsic adjuvant properties (Tan et al., 2018). The presence of LPS can activate the innate immune system, thereby enhancing a subsequent immune response.

Besides using OMVs as carrier for the delivery of antigens, they could also be loaded with therapeutic molecules. Escherichia coli OMVs decorated with human epidermal growth factor receptor 2 (HER2) specific antibodies and loaded with siRNAs were shown to target HER2-tumor cells and exert cytotoxic effects (Gujrati et al., 2014). The advantage of using natural OMVs over synthetic liposomes is their enhanced fusion capability with target cells (Wang et al., 2018). These examples altogether show the versatile applications of OMVs and the exciting progress made over the last decades.

\section{OMVs IN VACCINATION}

OMVs have been implicated in many different carrier functions, as described above. However, OMVs also have a great potential as endogenous vaccine. The presence of several antigens on OMVs limits the possibilities for pathogens to mutate all the target antigens present in the vaccine and thereby limits the possibility to generate vaccine escape variants. Furthermore, OMV isolation is relatively low-cost, compared to manufacturing of synthetic molecules for instance. This makes OMVs of great interest for vaccine development (van der Pol et al., 2015).

In vivo, OMVs have a wide variety of interactions with immune cells showing their potential to be used for immunization (Kaparakis-Liaskos and Ferrero, 2015; Cai et al., 2018). The first studies into immune responses evoked by OMVs already showed promising inductions of cytokines and chemokines in macrophages and other cell types. sOMVs isolated from Brucella melitensis were used to stimulate bone marrow-derived macrophages and showed induction of interleukin (IL)-6, IL-10, IL-12, or tumor necrosis factor (TNF) $\alpha$, depending on the LPS structure of the strain used (Avila-Caldern et al., 2012). sOMVs from E. coli were shown to induce CXCL1 expression in mouse endothelia, leading to an increased influx of neutrophils (Lee et al., 2018). Escherichia coli gOMVs, loaded with a Chlamydia muridarum antigen, elicited a neutralizing antibody response, in contrast to recombinant antigen (Bartolini et al., 2013). This was confirmed for several other heterologous antigens loaded in E. coli gOMVs (Fantappiè et al., 2014), showing the benefit of retaining native conformation of antigens in OMVs.

For some bacteria, studies on immunization with OMVs in mice have been performed and showed protection against subsequent infection. For example, immunization with sOMVs from Vibrio cholerae in mice induced immunoglobulin production and demonstrated a protective effect toward this bacterium in their offspring (Schild et al., 2008). Studies on E. coli sOMVs in mice revealed that immunization with sOMVs protected against sepsis and mainly induced the protective effect via $\mathrm{T}$ cell immunity (Kim et al., 2013). For Shigella flexneri, merged sOMVs were used to immunize mice and also this provided protection against a subsequent lethal bacterial Shigella challenge (Camacho et al., 2011). An sOMV-based vaccine against Burkholderia pseudomallei provided protection in a mouse model and even induced humoral immunity in a nonhuman primate immunization model (Petersen et al., 2014). In chicken, an sOMV-based vaccine against Salmonella enterica protected against a subsequent challenge and induced high expression of interferon $\gamma$ (Li et al., 2020a). All together the potential of OMVs for the use as a vaccine component seems promising. Induction and isolation methods will have consequences for immune properties of OMVs, which was shown for Acinetobacter baumannii. sOMVs and two types of vesicular structures prepared from the bacterial pellet were tested and while immunization with both types elicited protection against subsequent challenge, antibody profiles differed substantially (Li et al., 2020b). However, two types of OMV-based vaccine against Neisseria meningitidis are currently the only OMV-based vaccines licensed, MeNZB and Bexsero, and research into these will be discussed in more detail below (Oster et al., 2005; Acevedo et al., 2014; FDA, 2015).

\section{The Success Story of Neisseria meningitidis}

One Gram-negative bacterium for which a safe and effective OMV-based vaccine has been in use since 1990 is N. meningitidis (Holst et al., 2013). This capsule forming bacterium has several serogroups and for most serogroups vaccines have been developed, except for serogroup B, which is estimated to be the cause of $65 \%$ of all meningitis cases in children under 5 years of age in the United States and 51\% of total cases in Europe (Centers for Disease Control and Prevention, 2017; European Centre for Disease Prevention and Control, 2019). The vaccines for other $N$. meningitidis serogroups rely on recombinant capsular proteins, but for serogroup B the capsular protein resembles 
a molecule in the human brain (Finne et al., 1983). This provokes the risk of auto-immunity when used in a vaccine and therefore a different vaccine approach was necessary.

The vaccine approach for serogroup B was focused on $\mathrm{OM}$ proteins. To maintain stability and native fold of $\mathrm{OM}$ proteins, it is essential to utilize them in a membranous environment and therefore OMVs were considered as most promising for this approach. The most abundant OM protein in N. meningitidis OMVs was shown to be the porin protein PorA, which is also the most immunogenic protein (Granoff, 2010). Unfortunately, variation in PorA is substantial among various serogroup B strains and little cross-protection is observed (Sacchi et al., 2000). It was suggested that more than 20 different PorA molecules should be included in the vaccine to cover all $N$. meningitidis strains circulating worldwide (Sacchi et al., 2000). Therefore, no worldwide vaccine has been developed yet. However, OMV-based vaccines have proven to be very effective to control clonal outbreaks. Several outbreaks have occurred in the past, including in Cuba, Norway (Holst et al., 2009), New Zealand (Holst et al., 2013), and Normandy (Sevestre et al., 2017). Because these outbreaks were caused by a single $N$. meningitidis serogroup $B$ strain, a dOMV vaccine was employed to prevent further spread and causalities. Analysis of the immune responses elicited by the OMV-based vaccine in Normandy demonstrated that it indeed elicited short-lasting responses, but it also elicited larger strain coverage than expected (Sevestre et al., 2017). Effectiveness of OMV-based vaccines was determined to be $87 \%$ after 10 months for the vaccines used in Cuba and Norway (Holst et al., 2009), and around $80 \%$ in New Zealand (Holst et al., 2013). However, these numbers are not based on clinical efficacy trials and therefore have to be assessed critically. Nevertheless, OMV-based vaccines are a safe and effective measure to control clonal epidemics of $N$. meningitidis and might even show cross-protection (Trzewikoswki de Lima et al., 2019).

OMV-based vaccines for $N$. meningitidis used in clonal outbreaks were prepared using detergent extraction, and thus removal of large amounts of LPS, decreasing the reactogenicity of the vaccine and increasing the necessity of an external adjuvant. Currently, detergent free nOMVs from Neisseria are being developed, using EDTA (van de Waterbeemd et al., 2010, 2012). Additionally, OMV yields have been improved by deletion of the rmpM gene in the bacterium (van de Waterbeemd et al., 2010). This gene codes for a peptidoglycan-binding outer membrane protein. Removal of the $r m p M$ gene results in decreased attachment between the PG and OM, and thereby an increased formation of vesicles. Since OMVs were purified without detergents, no LPS was removed. To decrease toxicity of LPS, a second genetic modification has been implemented, by generating a knock-out of the IpxL1 gene (van Der Ley et al., 2001). Mutants lacking the acyltransferase lpxL1 produce LPS containing five acyl chains as opposed to the regular six. This altered LPS results in decreased activation of toll like receptor 4 (TLR4) and is therefore less reactogenic, but it does not affect bacterial growth (van Der Ley et al., 2001; Fransen et al., 2010). This ngOMV-based vaccine of Neisseria has shown promising results in clinical trials and no severe adverse effects have been observed (Keiser et al., 2011). Research has even shown the possibility of a continuous production of $N$. meningitidis gOMVs, without the use of EDTA (Gerritzen et al., 2019). This example shows how OMV-based vaccines could be a promising strategy for combatting diseases caused by Gram-negative bacteria. The different types of OMVs studied for $N$. meningitidis are summarized in Table 2.

\section{OMV-Vaccine Candidate: Bordetella pertussis}

Bordetella pertussis is a Gram-negative bacterium for which an OMV-based vaccine might be the optimal strategy for disease prevention. The bacterium is the causative agent for pertussis, or whooping cough, a disease most dangerous for infants (Cherry, 2016). Upon inhalation or ingestion of the bacterium, it adheres to ciliated cells and invades the lungs (Kilgore et al., 2016). Because $B$. pertussis attaches to and immobilizes the cilia, the infected individual cannot clear debris from the lungs and develops coughing fits. This results in the risk of suffocation, particularly in infants (Melvin et al., 2014).

Due to the severity of $B$. pertussis infection and the mortality caused in infants, vaccines were developed as soon as the causative agent of pertussis was identified in 1906 by Jules Bordet and Octave Gengou. The first pertussis vaccine was licensed in 1914 and consisted of whole-cell inactivated bacteria (Ligon, 1998). This whole-cell pertussis vaccine (wPv) provided satisfactory efficacy but due to adverse effects of the vaccine, like systemic fever, convulsions and even acute encephalopathy, most countries switched in the 1990s to an acellular pertussis vaccine $(\mathrm{aPv})$. $\mathrm{aPv}$ contains $3-5$ purified B. pertussis proteins

TABLE 2 | Overview of tested OMV types for Neisseria meningitidis and Bordetella pertussis and their results.

\begin{tabular}{|c|c|c|c|c|}
\hline Bacterium & OMV type & Modifications & Results & Remarks \\
\hline & dOMVs & None & 80-87\% effectiveness & Clonal outbreaks \\
\hline \multirow[t]{3}{*}{ Neisseria meningitidis } & ngOMVs & $\Delta \mathrm{rmpM}, \Delta \mathrm{lpxL} 1$ & 79\% effectiveness & $41-82 \%$ cross-reactivity \\
\hline & $\operatorname{lgOMVs}$ & PagL & 5-fold decrease in bacterial colonization & Compared to naïve mice \\
\hline & nOMVs & None & 5-fold decrease in bacterial colonization & Compared to naïve mice \\
\hline Bordetella pertussis & sOMVs & None & 5-fold decrease in bacterial colonization & Compared to naïve mice at day 63 \\
\hline
\end{tabular}

Neisseria meningitidis OMVs results are obtained in humans (Holst et al., 2009, 2013; Keiser et al., 2011), Bordetella pertussis OMV results are obtained from mice experiments (Roberts et al., 2008; Asensio et al., 2011; Raeven et al., 2016). 
and does not elicit adverse effects. However, aPv has shown waning immunity, partly because $B$. pertussis mutates vaccine antigens such as pertactin (Barkoff et al., 2019; Jayasundara et al., 2020). Additionally, the aPV does not evoke the effective $\mathrm{T}$ helper 1 cell (Th1)/T helper 17 cell (Th17) response that a natural infection evokes in humans, but a $\mathrm{T}$ helper 2 cell (Th2) response (Burdin et al., 2017). Furthermore, the current vaccine can prevent disease but not transmission as shown by studies in a baboon model (Pinto and Merkel, 2017). By this, $B$. pertussis can maintain itself in a population, causing disease in non-vaccinated individuals, such as infants.

The incidences of $B$. pertussis infections are increasing, despite high-vaccination coverage. Worldwide approximately 140,000 cases were reported in 2016, despite the vaccination coverage of approximately 90\% (WHO, 2016; CDC, 2017). This increase in the number of cases was observed around the same time the vaccination program for B. pertussis was changed in the 1990s. Therefore, development of an increased immunogenic $B$. pertussis vaccine that can elicit the right immunological response and maintain increased immunological memory has become a priority (Rumbo and Hozbor, 2014; Brennan, 2017; Debrie et al., 2019). Recently, the optimal administration of a $B$. pertussis vaccine was investigated in mouse experiments and was found to be intranasal, which might increase effectiveness of new vaccines (Raeven et al., 2018). However, experiments in baboons will give more relevant information, since their immune system is more representative of a human immune system.

Bordetella pertussis OMVs have been extensively studied as an alternative strategy for vaccine development, since $\mathrm{wPv}$ has shown adverse effects and $\mathrm{aPv}$ has shown waning immunity (Hozbor, 2017, 2019). Bordetella pertussis lOMVs have been studied first and induced using sonication methods. Additionally, the pagL gene was introduced in this bacterial strain, which removes one acyl chain of the LPS, to decrease LPS toxicity (therefore resulting in lgOMVs; Asensio et al., 2011). Immunization with these vesicles showed faster clearance of bacteria in the lungs of infected mice compared to non-immunized mice. Furthermore, immunization of mice with lgOMVs showed decreased gene expression of inflammatory cytokines compared to immunization with lOMVs. Previous attempts to detoxify LPS by genetic removal of acyl chains did not always lead to these results, sometimes endotoxic effects were even increased (Geurtsen et al., 2006). This is probably due to an increased LPS release upon modification, which resulted in increased TLR4 activation (Geurtsen et al., 2006). Recently, the immune response evoked by $B$. pertussis lOMVs was studied further and revealed to activate the inflammasome in mice and human macrophages (Elizagaray et al., 2020). However, since the lOMVs or lgOMVs were extracted using sonication, which disrupts the entire bacterial membrane, contamination of the OMV sample by other bacterial products could have occurred, or the loss of natural cargo, making the studied immune responses not relevant to in vivo produced sOMVs (Asensio et al., 2011).

In later studies, $B$. pertussis nOMVs have also been used in in vivo mice experiments (Roberts et al., 2008).
Immunization with $B$. pertussis nOMVs, extracted by EDTA, resulted in a rapid clearance of bacteria after challenge, similar to immunization with killed whole-cell $B$. pertussis. Characterization of $B$. pertussis nOMVs revealed that the presence of pertussis toxin and pertactin in the nOMVs is essential for evoking an effective immune response (Ormazábal et al., 2014). Bordetella pertussis nOMVs elicited a long-lasting protection, for up to 9 months in mice (Gaillard et al., 2014). However, it is unsure how this can be translated to humans.

More recently, $B$. pertussis sOMVs have been used to study the immune response. The adaptive immune responses evoked by these sOMVs have been characterized extensively in mice. Both immunization with sOMVs and heat-killed whole-cell B. pertussis evoked mixed Th1/Th2/Th17 responses but the sOMV-based vaccine seems to induce a different antibody response. After booster immunization, the antibody profile was dominated by IgG3 for the sOMV-based vaccine and IgG1 for the whole-cell based vaccine (Raeven et al., 2016). The most prominent antibody response was shown to be directed against BrkA, Vag8, and LOS, all outer membrane components (Raeven et al., 2015). Most importantly, the sOMV-based vaccine showed less pro-inflammatory cytokine production compared to the whole-cell vaccine (Raeven et al., 2016). This suggests that a sOMV-based vaccine could resolve any reactogenicity problems encountered by the whole-cell vaccine. All types of studied B. pertussis OMVs are summarized in Table 2.

\section{FUTURE PROSPECTS}

OMV-based vaccines have great potential for next generation vaccine development. Several challenges remain, such as yields of OMVs, after isolation and the composition and thereby immunogenicity and toxicity of the vesicles (van der Pol et al., 2015). While OMVs are a natural product and beneficial to the bacterium, no large quantities are produced during bacterial growth but there might be a rather simple solution to increase OMV yields. OMV release has been shown to increase upon stress, as described above. The most trivial stress a bacterium could experience is environmental stress, for instance, nutrient depletion, pressure, or temperature stress (van de Waterbeemd et al., 2013b). In Pseudomonas putida, it was shown that a heat shock of $55^{\circ} \mathrm{C}$ increased OMV release (von Bergen et al., 2012). Similarly, after treatment with higher temperatures B-band LPS export in OMVs was increased in P. aeruginosa (Eberlein et al., 2018). Recently it was shown that heat treatment also increased OMV production in B. pertussis (de Jonge et al., 2021). These heat-induced OMVs (hOMVs) were shown to still contain important antigens, which could be detected with antibodies. Furthermore, the same treatment was applied to $B$. bronchiseptica and the resulting OMVs were further characterized to ensure quality of the vesicles. hOMVs were stable up to $40^{\circ} \mathrm{C}$ and $\mathrm{sOMVs}$ even up to $50^{\circ} \mathrm{C}$. Additionally, hOMVs had a large increase in the amount of lysophospholipids, as was shown by lipidomic analysis. 
Despite these differences, hOMVs evoked a comparable immune response to spontaneous OMVs in vitro (Balhuizen et al., 2021). However, the quantities of LPS might still pose a problem and molecules to modulate the resulting immune response are needed.

AMPs were originally known for their antimicrobial function, but recently immunomodulatory functions have been described for these peptides as well (Hilchie et al., 2013; Hancock et al., 2016; van Harten et al., 2018; Mookherjee et al., 2020; Scheenstra et al., 2020). For example, the human cathelicidin antimicrobial peptide LL-37 has been shown to direct dendritic cell (DC) differentiation to promote a Th1 response (Davidson et al., 2004). This could be employed in vaccine development by steering the immune response to a desired Th1/Th17 response. Furthermore, the chicken cathelicidin 2 (CATH-2) was shown to induce several chemokines, suggesting that immunomodulatory mechanisms might be conserved among species (van Dijk et al., 2016; van Harten et al., 2018). On the other hand, LL-37 has also been shown to inhibit TLR4 activation on DCs by agonists such as LPS (Kandler et al., 2006). Likewise, CATH-2 was shown to neutralize LPS-induced TLR4 activation by interacting with LPS. This was shown in the context of non-viable bacteria, possibly as a mechanism to prevent an unnecessary immune response (Coorens et al., 2017; Scheenstra et al., 2020). Therefore, AMPs could decrease LPS-induced TLR4 activation in an OMV-based vaccine, as was recently been shown for B. bronchiseptica OMVs. When the porcine AMP, PMAP-36, was supplemented to isolated sOMVs and subsequently used to stimulate macrophages, cytokine secretion decreased (Balhuizen et al., 2021). Furthermore, a synthetic anti-endotoxin (non-AMP) peptide was also shown to decrease E. coli OMV-induced activation of human macrophages (Pfalzgraff et al., 2019). These results indicate that AMPs are the promising molecules for tailoring immune responses in vaccines, however, studies on other pathogens should reveal whether this mechanism is broadly applicable. Furthermore, tailor-made AMPs could be synthesized with desired immune modulating properties (Haney et al., 2017; Wuerth et al., 2017; Etayash et al., 2020).

\section{REFERENCES}

Acevedo, R., Fernández, S., Zayas, C., Acosta, A., Sarmiento, M. E., Ferro, V. A., et al. (2014). Bacterial outer membrane vesicles and vaccine applications. Front. Immunol. 5:121. doi: 10.3389/fimmu.2014.00121

Adu-Bobie, J., Lupetti, P., Brunelli, B., Granoff, D., Norais, N., Ferrari, G., et al. (2004). GNA33 of Neisseria meningitidis is a lipoprotein required for cell separation, membrane architecture, and virulence. Infect. Immun. 72, 1914-1919. doi: 10.1128/IAI.72.4.1914-1919.2004

Asensio, C. J. A., Gaillard, M. E., Moreno, G., Bottero, D., Zurita, E., Rumbo, M., et al. (2011). Outer membrane vesicles obtained from Bordetella pertussis Tohama expressing the lipid a deacylase PagL as a novel acellular vaccine candidate. Vaccine 29, 1649-1656. doi: 10.1016/j.vaccine.2010.12.068

Avila-Caldern, E. D., Lopez-Merino, A., Jain, N., Peralta, H., Lpez-Villegas, E. O., Sriranganathan, N., et al. (2012). Characterization of outer membrane vesicles from Brucella melitensis and protection induced in mice. Clin. Dev. Immunol. 2012:352493. doi: $10.1155 / 2012 / 352493$

Balhuizen, M. D., Versluis, C. M., van Harten, R. M., de Jonge, E. F., Brouwers, J. F., van de Lest, C. H. A., et al. (2021). PMAP-36 reduces the innate immune

\section{CONCLUSION}

OMVs are a promising tool for vaccine development, especially compared to acellular vaccines. The immunogenicity of OMV based vaccines is increased compared to acellular vaccines and the risk of evolutionary escape pathogens is almost diminished compared to using an acellular vaccine. Especially in cases where whole-cell approaches are not applicable, OMV-based vaccines pose a potential solution. However, some challenges lie ahead of the OMV-based vaccine field such as low yields and endotoxic effects due to the presence of LPS. Many solutions have been created such as extraction to increase vesicle yields or genetic modifications to both increase yields and decrease endotoxicity. However, these solutions often alter vesicles as such that their representation of the originating bacterium is no longer optimal. The use of spontaneous OMVs would circumvent this. To increase yields of sOMVs, a simple solution seems to be optimal: heat induction. To reduce LPS endotoxicity, host defense peptides show great potential. These peptides are known for their antimicrobial activity but additionally have shown to exhibit immunomodulatory activities such as the neutralization of LPS-induced TLR4 activation. Furthermore, they can steer immune responses, possibly into an ideal Th1/Th17 response. Concluding, induced OMVs are a promising future for bacterial vaccine development, with AMPs being a potential solution to the challenges that lie ahead.

\section{AUTHOR CONTRIBUTIONS}

MB designed the study. $\mathrm{MB}, \mathrm{EV}$, and $\mathrm{HH}$ wrote the manuscript. All authors contributed to the article and approved the submitted version.

\section{FUNDING}

This research was supported in part by NWO-TTW grant 14921 and 14924 to the Bac-Vactory 468 program.

response induced by Bordetella bronchiseptica-derived outer membrane vesicles. Curr. Res. Microbial. Sci. 2:100010. doi: 10.1016/j.crmicr.2020.100010

Barkoff, A. M., Mertsola, J., Pierard, D., Dalby, T., Hoegh, S. V., Guillot, S., et al. (2019). Pertactin-deficient Bordetella pertussis isolates: evidence of increased circulation in Europe, 1998 to 2015. Eur. Secur. 24:1700832. doi: 10.2807/1560-7917.ES.2019.24.7.1700832

Bartolini, E., Ianni, E., Frigimelica, E., Petracca, R., Galli, G., Scorza, F. B., et al. (2013). Recombinant outer membrane vesicles carrying Chlamydia muridarum HtrA induce antibodies that neutralize chlamydial infection in vitro. J. Extracell. Vesicles 2:20181. doi: 10.3402/jev.v2i0.20181

Bernadac, A., Gavioli, M., Lazzaroni, J. C., Raina, S., and Lloubès, R. (1998). Escherichia coli tol-pal mutants form outer membrane vesicles. J. Bacteriol. 180, 4872-4878. doi: 10.1128/jb.180.18.4872-4878.1998

Beveridge, T. J. (1999). Structures of gram-negative cell walls and their derived membrane vesicles. J. Bacteriol. 181, 4725-4733. doi: 10.1128/JB.181.16.4 725-4733.1999

Bitto, N. J., Chapman, R., Pidot, S., Costin, A., Lo, C., Choi, J., et al. (2017). Bacterial membrane vesicles transport their DNA cargo into host cells. Sci. Rep. 7:7072. doi: 10.1038/s41598-017-07288-4 
Bomberger, J. M., MacEachran, D. P., Coutermarsh, B. A., Ye, S., O’Toole, G. A., and Stanton, B. A. (2009). Long-distance delivery of bacterial virulence factors by Pseudomonas aeruginosa outer membrane vesicles. PLoS Pathog. 5:e1000382. doi: 10.1371/journal.ppat.1000382

Bonnington, K. E., and Kuehn, M. J. (2014). Protein selection and export via outer membrane vesicles. Biochim. Biophys. Acta 1843, 1612-1619. doi: 10.1016/j.bbamcr.2013.12.011

Bottero, D., Zurita, M. E., Gaillard, M. E., Bartel, E., Vercellini, C., and Hozbor, D. (2018). Membrane vesicles derived from Bordetella bronchiseptica: active constituent of a new vaccine against infections caused by this pathogen. Appl. Environ. Microbiol. 84:e01877-17. doi: 10.1128/AEM.01877-17

Brennan, M. (2017). A new whooping cough vaccine that may prevent colonization and transmission. Vaccine 5:43. doi: 10.3390/vaccines5040043

Bru, J. -L., Rawson, B., Trinh, C., Whiteson, K., Molin Høyland-Kroghsbo, N., and Siryaporn, A. (2019). PQS produced by the Pseudomonas aeruginosa stress response repels swarms away from bacteriophage and antibiotics. J. Bacteriol. 201:e00383-19. doi: 10.1128/JB.00383-19

Burdin, N., Handy, L. K., and Plotkin, S. A. (2017). What is wrong with pertussis vaccine immunity? The problem of waning effectiveness of pertussis vaccines. Cold Spring Harb. Perspect. Biol. 9:a029454. doi: 10.1101/cshperspect. a029454

Cai, W., Kesavan, D. K., Wan, J., Abdelaziz, M. H., Su, Z., and Xu, H. (2018). Bacterial outer membrane vesicles, a potential vaccine candidate in interactions with host cells based. Diagn. Pathol. 13:95. doi: 10.1186/s13000-018-0768-y

Camacho, A. I., de Souza, J., Sánchez-Gómez, S., Pardo-Ros, M., Irache, J. M., and Gamazo, C. (2011). Mucosal immunization with Shigella flexneri outer membrane vesicles induced protection in mice. Vaccine 29, 8222-8229. doi: $10.1016 /$ j.vaccine.2011.08.121

CDC (2017). Pertussis | Whooping Cough | Surveillance | Cases by Year | CDC. Pertussis (Whooping Cough). Available at: https://www.cdc.gov/pertussis/ surv-reporting/cases-by-year.html (Accessed March 20, 2020).

Centers for Disease Control and Prevention (2017). Meningococcal | Surveillance | CDC. Available at: https://www.cdc.gov/meningococcal/surveillance/index. html (Accessed January 5, 2021).

Chan, K. W., Shone, C., and Hesp, J. R. (2017). Antibiotics and iron-limiting conditions and their effect on the production and composition of outer membrane vesicles secreted from clinical isolates of extraintestinal pathogenic E. coli. Proteomics Clin. Appl. 11:1600091. doi: 10.1002/prca.201600091

Chen, L., Valentine, J. L., Huang, C. J., Endicott, C. E., Moeller, T. D., Rasmussen, J. A., et al. (2016). Outer membrane vesicles displaying engineered glycotopes elicit protective antibodies. Proc. Natl. Acad. Sci. U. S. A. 113, E3609-E3618. doi: 10.1073/pnas.1518311113

Cherry, J. D. (2016). Pertussis in young infants throughout the world. Clin. Infect. Dis. 63, S119-S122. doi: 10.1093/cid/ciw550

Ciofu, O. (2000). Chromosomal beta-lactamase is packaged into membrane vesicles and secreted from Pseudomonas aeruginosa. J. Antimicrob. Chemother. 45, 9-13. doi: $10.1093 / \mathrm{jac} / 45.1 .9$

Clifton, L. A., Skoda, M. W. A., Le Brun, A. P., Ciesielski, F., Kuzmenko, I., Holt, S. A., et al. (2015). Effect of divalent cation removal on the structure of gram-negative bacterial outer membrane models. Langmuir 31, 404-412. doi: $10.1021 / \mathrm{la} 504407 \mathrm{v}$

Collins, B. S. (2011). Gram-negative outer membrane vesicles in vaccine development. Discov. Med. 12, 7-15.

Coorens, M., Schneider, V. A. F., de Groot, A. M., van Dijk, A., Meijerink, M., Wells, J. M., et al. (2017). Cathelicidins inhibit Escherichia coli-induced TLR2 and TLR4 activation in a viability-dependent manner. J. Immunol. 199, 1418-1428. doi: 10.4049/jimmunol.1602164

Daleke-Schermerhorn, M. H., Felix, T., Soprova, Z., Ten Hagen-Jongman, C. M., Vikström, D., Majlessi, L., et al. (2014). Decoration of outer membrane vesicles with multiple antigens by using an autotransporter approach. Appl. Environ. Microbiol. 80, 5854-5865. doi: 10.1128/AEM.01941-14

Davidson, D. J., Currie, A. J., Reid, G. S. D., Bowdish, D. M. E., MacDonald, K. L., Ma, R. C., et al. (2004). The cationic antimicrobial peptide LL-37 modulates dendritic cell differentiation and dendritic cell-induced $\mathrm{T}$ cell polarization. J. Immunol. 172, 1146-1156. doi: 10.4049/jimmunol.172.2.1146

De Benedetto, G., Alfini, R., Cescutti, P., Caboni, M., Lanzilao, L., Necchi, F., et al. (2017). Characterization of O-antigen delivered by Generalized Modules for Membrane Antigens (GMMA) vaccine candidates against nontyphoidal Salmonella. Vaccine 35, 419-426. doi: 10.1016/j.vaccine.2016.11.089 de Jonge, E. F., Balhuizen, M. D., van Boxtel, R., Wu, J., Haagsman, H. P., and Tommassen, J. (2021). Heat shock enhances outer-membrane vesicle release in Bordetella spp. Curr. Res. Microbial. Sci. 2:100009. doi: 10.1016/j. crmicr.2020.100009

Deatherage, B. L., Lara, J. C., Bergsbaken, T., Barrett, S. L. R., Lara, S., and Cookson, B. T. (2009). Biogenesis of bacterial membrane vesicles. Mol. Microbiol. 72, 1395-1407. doi: 10.1111/j.1365-2958.2009.06731.x

Debrie, A. -S., Mielcarek, N., Lecher, S., Roux, X., Sirard, J. -C., and Locht, C. (2019). Early protection against pertussis induced by live attenuated Bordetella pertussis BPZE1 depends on TLR4. J. Immunol. 203, 3293-3300. doi: 10.4049/ jimmunol.1901102

Dorward, D. W., Garon, C. F., and Judd, R. C. (1989). Export and intercellular transfer of DNA via membrane blebs of Neisseria gonorrhoeae. J. Bacteriol. 171, 2499-2505. doi: 10.1128/jb.171.5.2499-2505.1989

Duperthuy, M., Sjöström, A. E., Sabharwal, D., Damghani, F., Uhlin, B. E., and Wai, S. N. (2013). Role of the vibrio cholerae matrix protein Bap1 in cross-resistance to antimicrobial peptides. PLoS Pathog. 9:e1003620. doi: 10.1371/journal.ppat.1003620

Eberlein, C., Baumgarten, T., Starke, S., and Heipieper, H. J. (2018). Immediate response mechanisms of Gram-negative solvent-tolerant bacteria to cope with environmental stress: cis-trans isomerization of unsaturated fatty acids and outer membrane vesicle secretion. Appl. Microbiol. Biotechnol. 102, 2583-2593. doi: 10.1007/s00253-018-8832-9

Elhenawy, W., Bording-Jorgensen, M., Valguarnera, E., Haurat, M. F., Wine, E., and Feldman, M. F. (2016). LPS remodeling triggers formation of outer membrane vesicles in Salmonella. MBio 7:e00940-16. doi: 10.1128/ mBio.00940-16

Elizagaray, M. L., Gomes, M. T. R., Guimaraes, E. S., Rumbo, M., Hozbor, D. F., Oliveira, S. C., et al. (2020). Canonical and non-canonical inflammasome activation by outer membrane vesicles derived from Bordetella pertussis. Front. Immunol. 11:1879. doi: 10.3389/fimmu.2020.01879

Ellis, T. N., and Kuehn, M. J. (2010). Virulence and immunomodulatory roles of bacterial outer membrane vesicles. Microbiol. Mol. Biol. Rev. 74, 81-94. doi: 10.1128/MMBR.00031-09

Etayash, H., Pletzer, D., Kumar, P., Straus, S. K., and Hancock, R. E. W. (2020). Cyclic derivative of host-defense peptide IDR-1018 improves proteolytic stability, suppresses inflammation, and enhances in vivo activity. J. Med. Chem. 63, 9228-9236. doi: 10.1021/acs.jmedchem.0c00303

European Centre for Disease Prevention and Control (2019). Invasive meningococcal disease annual epidemiological report for 2017. Annual Epidemiological Report on Communicable Diseases in Europe. Available at: http://ecdc.europa.eu/sites/portal/files/documents/AER_for_2017-invasivemeningococcal-disease.pdf (Accessed January 5, 2021).

Fantappiè, L., de Santis, M., Chiarot, E., Carboni, F., Bensi, G., Jousson, O., et al. (2014). Antibody-mediated immunity induced by engineered Escherichia coli OMVs carrying heterologous antigens in their lumen. J. Extracell. Vesicles 3:24015. doi: 10.3402/jev.v3.24015

FDA (2015). FDA approves a second vaccine to prevent serogroup B meningococcal disease. U.S. Food and Drug Administration. Available at: https://www.fda. gov/news-events/press-announcements/first-vaccine-approved-fda-preventserogroup-b-meningococcal-disease (Accessed December 17, 2020).

Ferrari, G., Garaguso, I., Adu-Bobie, J., Doro, F., Taddei, A. R., Biolchi, A., et al. (2006). Outer membrane vesicles from group B Neisseria meningitidis $\Delta$ gna33 mutant: proteomic and immunological comparison with detergentderived outer membrane vesicles. Proteomics 6, 1856-1866. doi: 10.1002/ pmic. 200500164

Finne, J., Leinonen, M., and Mäkelä, P. H. (1983). Antigenic similarities between brain components and bacteria causing meningitis. Implications for vaccine development and pathogenesis. Lancet 2, 355-357. doi: 10.1016/S01406736(83)90340-9

Fransen, F., Hamstra, H. J., Boog, C. J., van Putten, J. P., van Den Dobbelsteen, G. P. J. M., and van Der Ley, P. (2010). The structure of Neisseria meningitidis lipid A determines outcome in experimental meningococcal disease. Infect. Immun. 78, 3177-3186. doi: 10.1128/IAI.01311-09

Gaillard, M. E., Bottero, D., Errea, A., Ormazábal, M., Zurita, M. E., and Moreno, G., et al. (2014). Acellular pertussis vaccine based on outer membrane vesicles capable of conferring both long-lasting immunity and protection against different strain genotypes. Vaccine 32, 931-937. doi: 10.1016/j. vaccine.2013.12.048 
Gasperini, G., Arato, V., Pizza, M., Aricò, B., and Leuzzi, R. (2017). Physiopathological roles of spontaneously released outer membrane vesicles of Bordetella pertussis. Future Microbiol. 12, 1247-1259. doi: 10.2217/ fmb-2017-0064

Gasperini, G., Biagini, M., Arato, V., Gianfaldoni, C., Vadi, A., Norais, N., et al. (2018). Outer membrane vesicles (OMV)-based and proteomics-driven antigen selection identifies novel factors contributing to Bordetella pertussis adhesion to epithelial cells. Mol. Cell. Proteomics 17, 205-215. doi: 10.1074/ mcp.RA117.000045

Gerke, C., Colucci, A. M., Giannelli, C., Sanzone, S., Vitali, C. G., Sollai, L., et al. (2015). Production of a Shigella sonnei vaccine based on generalized modules for membrane antigens (GMMA), 1790GAHB. PLoS One 10:e0134478. doi: 10.1371/journal.pone.0134478

Gerritzen, M. J. H., Martens, D. E., Wijffels, R. H., van der Pol, L., and Stork, M. (2017). Bioengineering bacterial outer membrane vesicles as vaccine platform. Biotechnol. Adv. 35, 565-574. doi: 10.1016/j.biotechadv.2017.05.003

Gerritzen, M. J. H., Stangowez, L., Van De Waterbeemd, B., Martens, D. E., Wijffels, R. H., and Stork, M. (2019). Continuous production of Neisseria meningitidis outer membrane vesicles. Appl. Microbiol. Biotechnol. 103, 9401-9410. doi: 10.1007/s00253-019-10163-z

Geurtsen, J., Steeghs, L., Hamstra, H. J., Ten Hove, J., De Haan, A., Kuipers, B., et al. (2006). Expression of the lipopolysaccharide-modifying enzymes PagP and PagL modulates the endotoxic activity of Bordetella pertussis. Infect. Immun. 74, 5574-5585. doi: 10.1128/IAI.00834-06

Gnopo, Y. M. D., Watkins, H. C., Stevenson, T. C., DeLisa, M. P., and Putnam, D. (2017). Designer outer membrane vesicles as immunomodulatory systemsreprogramming bacteria for vaccine delivery. Adv. Drug Deliv. Rev. 114, 132-142. doi: 10.1016/j.addr.2017.05.003

Godlewska, R. (2019). Influence of environmental and genetic factors on proteomic profiling of outer membrane vesicles from Campylobacter jejuni. Pol. J. Microbiol. 68, 255-261. doi: 10.33073/pjm-2019-027

Granoff, D. M. (2010). Review of meningococcal group B vaccines. Clin. Infect. Dis. 50, S54-S65. doi: 10.1086/648966

Gujrati, V., Kim, S., Kim, S. H., Min, J. J., Choy, H. E., Kim, S. C., et al. (2014). Bioengineered bacterial outer membrane vesicles as cell-specific drug-delivery vehicles for cancer therapy. ACS Nano 8, 1525-1537. doi: 10.1021/nn405724x

Hancock, R. E. W., Haney, E. F., and Gill, E. E. (2016). The immunology of host defence peptides: beyond antimicrobial activity. Nat. Rev. Immunol. 16, 321-334. doi: 10.1038/nri.2016.29

Haney, E. F., Wu, B. C., Lee, K., Hilchie, A. L., and Hancock, R. E. W. (2017). Aggregation and its influence on the immunomodulatory activity of synthetic innate defense regulator peptides. Cell Chem. Biol. 24, 969.e4-980.e4. doi: 10.1016/j.chembiol.2017.07.010

Hart, J. R. (2000). "Ethylenediaminetetraacetic acid and related chelating agents" in Ullmann's encyclopedia of industrial chemistry. ed. C. Ley (Weinheim, Germany: Wiley-VCH Verlag GmbH \& Co. KGaA).

Haurat, M. F., Aduse-Opoku, J., Rangarajan, M., Dorobantu, L., Gray, M. R., Curtis, M. A., et al. (2011). Selective sorting of cargo proteins into bacterial membrane vesicles. J. Biol. Chem. 286, 1269-1276. doi: 10.1074/jbc. M110.185744

Hazlett, L., and Wu, M. (2011). Defensins in innate immunity. Cell Tissue Res. 343, 175-188. doi: 10.1007/s00441-010-1022-4

Henry, T., Pommier, S., Journet, L., Bernadac, A., Gorvel, J. P., and Lloubès, R. (2004). Improved methods for producing outer membrane vesicles in Gramnegative bacteria. Res. Microbiol. 155, 437-446. doi: 10.1016/j.resmic.2004.04.007

Hilchie, A. L., Wuerth, K., and Hancock, R. E. W. (2013). Immune modulation by multifaceted cationic host defense (antimicrobial) peptides. Nat. Chem. Biol. 9, 761-768. doi: 10.1038/nchembio.1393

Holst, J., Martin, D., Arnold, R., Huergo, C. C., Oster, P., O'Hallahan, J., et al. (2009). Properties and clinical performance of vaccines containing outer membrane vesicles from Neisseria meningitidis. Vaccine 27, B3-B12. doi: 10.1016/j.vaccine.2009.04.071

Holst, J., Oster, P., Arnold, R., Tatley, M., Næss, L., Aaberge, I., et al. (2013). Vaccines against meningococcal serogroup $\mathrm{B}$ disease containing outer membrane vesicles (OMV): lessons from past programs and implications for the future. Hum. Vaccin. Immunother. 9, 1241-1253. doi: 10.4161/hv.24129

Hozbor, D. F. (2017). Outer membrane vesicles: an attractive candidate for pertussis vaccines. Expert Rev. Vaccines 16, 193-196. doi: 10.1080/14760584.2017.1276832
Hozbor, D. (2019). "New pertussis vaccines: a need and a challenge" in Advances in experimental medicine and biology. Vol. 1183. eds. G. Fedele and C. M. Ausiello (Springer), 115-126.

Jayasundara, D., Lee, E., Octavia, S., Lan, R., Tanaka, M. M., and Wood, J. G. (2020). Emergence of pertactin-deficient pertussis strains in Australia can be explained by models of vaccine escape. Epidemics 31:100388. doi: 10.1016/j. epidem.2020.100388

Jha, C., Ghosh, S., Gautam, V., Malhotra, P., and Ray, P. (2017). In vitro study of virulence potential of Acinetobacter baumannii outer membrane vesicles. Microb. Pathog. 111, 218-224. doi: 10.1016/j.micpath.2017.08.048

Jones, E. J., Booth, C., Fonseca, S., Parker, A., Cross, K., Miquel-Clopés, A., et al. (2020). The uptake, trafficking, and biodistribution of Bacteroides thetaiotaomicron generated outer membrane vesicles. Front. Microbiol. 11:57. doi: $10.3389 /$ fmicb.2020.00057

Jong, W. S., Daleke-Schermerhorn, M. H., Vikström, D., Ten Hagen-Jongman, C. M., de Punder, K., van der Wel, N. N., et al. (2014). An autotransporter display platform for the development of multivalent recombinant bacterial vector vaccines. Microb. Cell Factories 13:162. doi: 10.1186/s12934-014-0162-8

Kadurugamuwa, J. L., and Beveridge, T. J. (1995). Virulence factors are released from Pseudomonas aeruginosa in association with membrane vesicles during normal growth and exposure to gentamicin: a novel mechanism of enzyme secretion. J. Bacteriol. 177, 3998-4008. doi: 10.1128/jb.177.14.3998-4008.1995

Kadurugamuwa, J. L., and Beveridge, T. J. (1996). Bacteriolytic effect of membrane vesicles from Pseudomonas aeruginosa on other bacteria including pathogens: conceptually new antibiotics. J. Bacteriol. 178, 2767-2774. doi: 10.1128/ JB.178.10.2767-2774.1996

Kadurugamuwat, J. L., and Beveridge, T. J. (1999). Membrane vesicles derived from Pseudomonas aeruginosa and Shigella flexneri can be integrated into the surfaces of other Gram-negative bacteria. Microbiology 145, 2051-2060. doi: 10.1099/13500872-145-8-2051

Kandler, K., Shaykhiev, R., Kleemann, P., Klescz, F., Lohoff, M., Vogelmeier, C., et al. (2006). The anti-microbial peptide LL-37 inhibits the activation of dendritic cells by TLR ligands. Int. Immunol. 18, 1729-1736. doi: 10.1093/ intimm/dxl107

Kaparakis-Liaskos, M., and Ferrero, R. L. (2015). Immune modulation by bacterial outer membrane vesicles. Nat. Rev. Immunol. 15, 375-387. doi: 10.1038/nri3837

Keiser, P. B., Biggs-Cicatelli, S., Moran, E. E., Schmiel, D. H., Pinto, V. B., Burden, R. E., et al. (2011). A phase 1 study of a meningococcal native outer membrane vesicle vaccine made from a group B strain with deleted lpxL1 and synX, over-expressed factor $\mathrm{H}$ binding protein, two PorAs and stabilized OpcA expression. Vaccine 29, 1413-1420. doi: 10.1016/j.vaccine.2010.12.039

Kesavan, D., Vasudevan, A., Wu, L., Chen, J., Su, Z., Wang, S., et al. (2020). Integrative analysis of outer membrane vesicles proteomics and whole-cell transcriptome analysis of eravacycline induced Acinetobacter baumannii strains. BMC Microbiol. 20:31. doi: 10.1186/s12866-020-1722-1

Kilgore, P. E., Salim, A. M., Zervos, M. J., and Schmitt, H. J. (2016). Pertussis: microbiology, disease, treatment, and prevention. Clin. Microbiol. Rev. 29, 449-486. doi: 10.1128/CMR.00083-15

Kim, O. Y., Hong, B. S., Park, K. -S., Yoon, Y. J., Choi, S. J., Lee, W. H., et al. (2013). Immunization with Escherichia coli outer membrane vesicles protects bacteria-induced lethality via Th1 and Th17 cell responses. J. Immunol. 190, 4092-4102. doi: 10.4049/jimmunol.1200742

Klimentová, J., and Stulík, J. (2015). Methods of isolation and purification of outer membrane vesicles from gram-negative bacteria. Microbiol. Res. 170, 1-9. doi: 10.1016/j.micres.2014.09.006

Koeppen, K., Hampton, T. H., Jarek, M., Scharfe, M., Gerber, S. A., Mielcarz, D. W., et al. (2016). A novel mechanism of host-pathogen interaction through sRNA in bacterial outer membrane vesicles. PLoS Pathog. 12:e1005672. doi: 10.1371/journal.ppat.1005672

Kohl, P., Zingl, F. G., Eichmann, T. O., and Schild, S. (2018). "Isolation of outer membrane vesicles including their quantitative and qualitative analyses" in Methods in molecular biology. ed. A. E. Sikora (New York, NY: Humana Press), 117-134.

Kolling, G. L., and Matthews, K. R. (1999). Export of virulence genes and shiga toxin by membrane vesicles of Escherichia coli O157:H7. Appl. Environ. Microbiol. 65, 1843-1848. doi: 10.1128/AEM.65.5.1843-1848.1999

Kulkarni, H. M., and Jagannadham, M. V. (2014). Biogenesis and multifaceted roles of outer membrane vesicles from Gram-negative bacteria. Microbiology 160, 2109-2121. doi: 10.1099/mic.0.079400-0 
Kulkarni, H. M., Nagaraj, R., and Jagannadham, M. V. (2015). Protective role of E. coli outer membrane vesicles against antibiotics. Microbiol. Res. 181, 1-7. doi: 10.1016/j.micres.2015.07.008

Kulp, A., and Kuehn, M. J. (2010). Biological functions and biogenesis of secreted bacterial outer membrane vesicles. Annu. Rev. Microbiol. 64, 163-184. doi: 10.1146/annurev.micro.091208.073413

Lappann, M., Otto, A., Becher, D., and Vogel, U. (2013). Comparative proteome analysis of spontaneous outer membrane vesicles and purified outer membranes of Neisseria meningitidis. J. Bacteriol. 195, 4425-4435. doi: 10.1128/JB.00625-13

Lee, J., Kim, O. Y., and Gho, Y. S. (2016). Proteomic profiling of Gram-negative bacterial outer membrane vesicles: current perspectives. Proteomics Clin. Appl. 10, 897-909. doi: 10.1002/prca.201600032

Lee, J., Yoon, Y. J., Kim, J. H., Dinh, N. T. H., Go, G., Tae, S., et al. (2018). Outer membrane vesicles derived from Escherichia coli regulate neutrophil migration by induction of endothelial IL-8. Front. Microbiol. 9:2268. doi: 10.3389/fmicb.2018.02268

Li, S., Chen, D. -Q., Ji, L., Sun, S., Jin, Z., Jin, Z. -L., et al. (2020b). Development of different methods for preparing Acinetobacter baumannii outer membrane vesicles vaccine: impact of preparation method on protective efficacy. Front. Immunol. 11:1069. doi: 10.3389/fimmu.2020.01069

Li, Q., Ren, J., Xian, H., Yin, C., Yuan, Y., Li, Y., et al. (2020a). rOmpF and OMVs as efficient subunit vaccines against Salmonella enterica serovar Enteritidis infections in poultry farms. Vaccine 38, 7094-7099. doi: 10.1016/j. vaccine.2020.08.074

Ligon, B. L. (1998). Pertussis: an historical review of the research and of the development of whole-cell and acellular vaccines. Semin. Pediatr. Infect. Dis. 9, 168-178. doi: 10.1016/S1045-1870(98)80068-X.

Manning, A. J., and Kuehn, M. J. (2011). Contribution of bacterial outer membrane vesicles to innate bacterial defense. BMC Microbiol. 11:258. doi: 10.1186/1471-2180-11-258

Manning, A. J., and Kuehn, M. J. (2013). Functional advantages conferred by extracellular prokaryotic membrane vesicles. J. Mol. Microbiol. Biotechnol. 23, 131-141. doi: 10.1159/000346548

Maredia, R., Devineni, N., Lentz, P., Dallo, S. F., Yu, J., Guentzel, N., et al. (2012). Vesiculation from Pseudomonas aeruginosa under SOS. Sci. World J. 2012:402919. doi: 10.1100/2012/402919

Mashburn, L. M., and Whiteley, M. (2005). Membrane vesicles traffic signals and facilitate group activities in a prokaryote. Nature 437, 422-425. doi: 10.1038 /nature 03925

McBroom, A. J., Johnson, A. P., Vemulapalli, S., and Kuehn, M. J. (2006). Outer membrane vesicle production by Escherichia coli is independent of membrane instability. J. Bacteriol. 188, 5385-5392. doi: 10.1128/JB.00498-06

McBroom, A. J., and Kuehn, M. J. (2007). Release of outer membrane vesicles by Gram-negative bacteria is a novel envelope stress response. Mol. Microbiol. 63, 545-558. doi: 10.1111/j.1365-2958.2006.05522.x

Melvin, J. A., Scheller, E. V., Miller, J. F., and Cotter, P. A. (2014). Bordetella pertussis pathogenesis: current and future challenges. Nat. Rev. Microbiol. 12, 274-288. doi: 10.1038/nrmicro3235

Michel, L. V., Gallardo, L., Konovalova, A., Bauer, M., Jackson, N., Zavorin, M., et al. (2020). Ampicillin triggers the release of Pal in toxic vesicles from Escherichia coli. Int. J. Antimicrob. Agents 56:106163. doi: 10.1016/j.ijantimicag. 2020.106163

Micoli, F., Alfini, R., Di Benedetto, R., Necchi, F., Schiavo, F., Mancini, F., et al. (2020). GMMA is a versatile platform to design effective multivalent combination vaccines. Vaccine 8:540. doi: 10.3390/vaccines 8030540

Mookherjee, N., Anderson, M. A., Haagsman, H. P., and Davidson, D. J. (2020). Antimicrobial host defence peptides: functions and clinical potential. Nat. Rev. Drug Discov. 19, 311-332. doi: 10.1038/s41573-019-0058-8

Murray, B. O., Dawson, R. A., Alsharaf, L. M., and Anne Winter, J. (2020). Protective effects of Helicobacter pylori membrane vesicles against stress and antimicrobial agents. Microbiology 166, 751-758. doi: 10.1099/mic.0.000934

Ojima, Y., Sawabe, T., Konami, K., and Azuma, M. (2020). Construction of hypervesiculation Escherichia coli strains and application for secretory protein production. Biotechnol. Bioeng. 117, 701-709. doi: 10.1002/bit.27239

Ormazábal, M., Bartel, E., Gaillard, M. E., Bottero, D., Errea, A., and Zurita, M. E., et al. (2014). Characterization of the key antigenic components of pertussis vaccine based on outer membrane vesicles. Vaccine 32, 6084-6090. doi: 10.1016/j.vaccine.2014.08.084
Oster, P., Lennon, D., O’Hallahan, J., Mulholland, K., Reid, S., and Martin, D. (2005). MeNZB: a safe and highly immunogenic tailor-made vaccine against the New Zealand Neisseria meningitidis serogroup B disease epidemic strain. Vaccine 23, 2191-2196. doi: 10.1016/j.vaccine.2005.01.063

Pérez-Cruz, C., Cañas, M. -A., Giménez, R., Badia, J., Mercade, E., Baldomà, L., et al. (2016). Membrane vesicles released by a hypervesiculating Escherichia coli Nissle 1917 tolR mutant are highly heterogeneous and show reduced capacity for epithelial cell interaction and entry. PLoS One 11:e0169186. doi: 10.1371/journal.pone.0169186

Petersen, H., Nieves, W., Russell-Lodrigue, K., Roy, C. J., and Morici, L. A. (2014). Evaluation of a Burkholderia Pseudomallei outer membrane vesicle vaccine in nonhuman primates. Procedia Vaccinol. 8, 38-42. doi: 10.1016/j. provac.2014.07.007

Pfalzgraff, A., Correa, W., Heinbockel, L., Schromm, A. B., Lübow, C., Gisch, N., et al. (2019). LPS-neutralizing peptides reduce outer membrane vesicleinduced inflammatory responses. Biochim. Biophys. Acta Mol. Cell Biol. Lipids 1864, 1503-1513. doi: 10.1016/j.bbalip.2019.05.018

Pinto, M. V., and Merkel, T. J. (2017). Pertussis disease and transmission and host responses: insights from the baboon model of pertussis. J. Infect. 74, S114-S119. doi: 10.1016/S0163-4453(17)30201-3

Premjani, V., Tilley, D., and Gruenheid, S., Le Moual, H. , and Samis, J. A. (2014). Enterohemorrhagic Escherichia coli OmpT regulates outer membrane vesicle biogenesis. FEMS Microbiol. Lett. 355, 185-192. doi: 10.1111/15746968.12463

Raeven, R. H., Brummelman, J., Pennings, J. L. A., van der Maas, L., Helm, K., Tilstra, W., et al. (2018). Molecular and cellular signatures underlying superior immunity against Bordetella pertussis upon pulmonary vaccination. Mucosal Immunol. 11, 979-993. doi: 10.1038/mi.2017.81

Raeven, R. H. M., Brummelman, J., Pennings, J. L. A., van Der Maas, L., Tilstra, W., Helm, K., et al. (2016). Bordetella pertussis outer membrane vesicle vaccine confers equal efficacy in mice with milder inflammatory responses compared to a whole-cell vaccine. Sci. Rep. 6:38240. doi: 10.1038/ srep38240

Raeven, R. H. M., van Der Maas, L., Tilstra, W., Uittenbogaard, J. P., Bindels, T. H. E., Kuipers, B., et al. (2015). Immunoproteomic profiling of Bordetella pertussis outer membrane vesicle vaccine reveals broad and balanced humoral immunogenicity. J. Proteome Res. 14, 2929-2942. doi: 10.1021/acs.jproteome.5b00258

Roberts, R., Moreno, G., Bottero, D., Gaillard, M. E., Fingermann, M., Graieb, A., et al. (2008). Outer membrane vesicles as acellular vaccine against pertussis. Vaccine 26, 4639-4646. doi: 10.1016/j.vaccine.2008.07.004

Roier, S., Zingl, F. G., Cakar, F., Durakovic, S., Kohl, P., Eichmann, T. O., et al. (2016). A novel mechanism for the biogenesis of outer membrane vesicles in Gram-negative bacteria. Microbial. Cell 3, 257-259. doi: 10.1038/ ncomms 10515

Roszkowiak, J., Jajor, P., Guła, G., Gubernator, J., Żak, A., Drulis-Kawa, Z., et al. (2019). Interspecies outer membrane vesicles (OMVs) modulate the sensitivity of pathogenic bacteria and pathogenic yeasts to cationic peptides and serum complement. Int. J. Mol. Sci. 20:5577. doi: 10.3390/ijms20225577

Rumbo, C., Fernández-Moreira, E., Merino, M., Poza, M., Mendez, J. A., Soares, N. C., et al. (2011). Horizontal transfer of the OXA-24 carbapenemase gene via outer membrane vesicles: a new mechanism of dissemination of carbapenem resistance genes in Acinetobacter baumannii. Antimicrob. Agents Chemother. 55, 3084-3090. doi: 10.1128/AAC.00929-10

Rumbo, M., and Hozbor, D. (2014). Development of improved pertussis vaccine. Hum. Vaccin. Immunother. 10, 2450-2453. doi: 10.4161/hv.29253

Sacchi, C. T., Whitney, A. M., Popovic, T., Beall, D. S., Reeves, M. W., Plikaytis, B. D., et al. (2000). Diversity and prevalence of PorA types in Neisseria meningitidis serogroup B in the United States, 1992-1998. J. Infect. Dis. 182, 1169-1176. doi: 10.1086/315833

Scheenstra, M. R., van Harten, R. M., Veldhuizen, E. J. A., Haagsman, H. P., and Coorens, M. (2020). Cathelicidins modulate TLR-activation and inflammation. Front. Immunol. 11:1137. doi: 10.3389/fimmu.2020.01137

Schertzer, J. W., and Whiteley, M. (2012). A bilayer-couple model of bacterial outer membrane vesicle biogenesis. MBio 3:e00297-11. doi: 10.1128/mBio. 00297-11

Schild, S., Nelson, E. J., and Camilli, A. (2008). Immunization with Vibrio cholerae outer membrane vesicles induces protective immunity in mice. Infect. Immun. 76, 4554-4563. doi: 10.1128/IAI.00532-08 
Schneider, V. A. F., Coorens, M., Ordonez, S. R., Tjeerdsma-Van Bokhoven, J. L. M., Posthuma, G., van Dijk, A., et al. (2016). Imaging the antimicrobial mechanism(s) of cathelicidin-2. Sci. Rep. 6, 1-11. doi: 10.1038/srep32948

Schneider, V. A. F., Coorens, M., Tjeerdsma-van Bokhoven, J. L. M., Posthuma, G., van Dijk, A., Veldhuizen, E. J. A., et al. (2017). Imaging the antistaphylococcal activity of CATH-2: mechanism of attack and regulation of inflammatory response. mSphere 2:e0370-17. doi: 10.1128/mSphere.00370-17

Schooling, S. R., and Beveridge, T. J. (2006). Membrane vesicles: an overlooked component of the matrices of biofilms. J. Bacteriol. 188, 5945-5957. doi: 10.1128/JB.00257-06

Schwechheimer, C., and Kuehn, M. J. (2013). Synthetic effect between envelope stress and lack of outer membrane vesicle production in Escherichia coli. J. Bacteriol. 195, 4161-4173. doi: 10.1128/JB.02192-12

Schwechheimer, C., and Kuehn, M. J. (2015). Outer-membrane vesicles from Gram-negative bacteria: biogenesis and functions. Nat. Rev. Microbiol. 13, 605-619. doi: 10.1038/nrmicro3525

Schwechheimer, C., Kulp, A., and Kuehn, M. J. (2014). Modulation of bacterial outer membrane vesicle production by envelope structure and content. BMC Microbiol. 14:324. doi: 10.1186/s12866-014-0324-1

Schwechheimer, C., Sullivan, C. J., and Kuehn, M. J. (2013). Envelope control of outer membrane vesicle production in Gram-negative bacteria. Biochemistry 52, 3031-3040. doi: 10.1021/bi400164t

Sevestre, J., Hong, E., Delbos, V., Terrade, A., Mallet, E., Deghmane, A. E., et al. (2017). Durability of immunogenicity and strain coverage of MenBvac, a meningococcal vaccine based on outer membrane vesicles: lessons of the Normandy campaign. Vaccine 35, 4029-4033. doi: 10.1016/j.vaccine.2017.05.065

Sonntag, I., Schwarz, H., Hirota, Y., and Henning, U. (1978). Cell envelope and shape of Escherichia coli: multiple mutants missing the outer membrane lipoprotein and other major outer membrane proteins. J. Bacteriol. 136, 280-285. doi: 10.1128/JB.136.1.280-285.1978

Stevenson, T. C., Cywes-Bentley, C., Moeller, T. D., Weyant, K. B., Putnam, D., Chang, Y. F., et al. (2018). Immunization with outer membrane vesicles displaying conserved surface polysaccharide antigen elicits broadly antimicrobial antibodies. Proc. Natl. Acad. Sci. U. S. A. 115, E3106-E3115. doi: 10.1073/ pnas. 1718341115

Takaki, K., Tahara, Y. O., Nakamichi, N., Hasegawa, Y., Shintani, M., Ohkuma, M., et al. (2020). Multilamellar and multivesicular outer membrane vesicles produced by a Buttiauxella agrestis tolB mutant. Appl. Environ. Microbiol. 86, 1-15. doi: 10.1128/AEM.01131-20

Tan, K., Li, R., Huang, X., and Liu, Q. (2018). Outer membrane vesicles: current status and future direction of these novel vaccine adjuvants. Front. Microbiol. 9:783. doi: 10.3389/fmicb.2018.00783

Thomas, K. J., and Rice, C. V. (2014). Revised model of calcium and magnesium binding to the bacterial cell wall. Biometals 27, 1361-1370. doi: 10.1007/ s10534-014-9797-5

Trzewikoswki de Lima, G., and Portilho, A. I., and De Gaspari, E. (2019). Cross-reactivity with Brazilian strains of Neisseria meningitidis B after immunization with outer membrane vesicles. Ther. Adv. Vaccines Immunother. 7:251513551989482. doi: 10.1177/2515135519894825

Valguarnera, E., and Feldman, M. F. (2017). "Glycoengineered outer membrane vesicles as a platform for vaccine development" in Methods in enzymology. ed. B. Imperiali (Amsterdam: Elsevier Inc.), 285-310.

van de Waterbeemd, B., Streefland, M., van der Ley, P., Zomer, B., van Dijken, H., Martens, D., et al. (2010). Improved OMV vaccine against Neisseria meningitidis using genetically engineered strains and a detergent-free purification process. Vaccine 28, 4810-4816. doi: 10.1016/j.vaccine.2010.04.082

van de Waterbeemd, B., Streefland, M., van Keulen, L., van den IJssel, J., de Haan, A., Eppink, M. H., et al. (2012). Identification and optimization of critical process parameters for the production of NOMV vaccine against Neisseria meningitidis. Vaccine 30, 3683-3690. doi: 10.1016/j.vaccine.2012.03.028

van de Waterbeemd, B., Zomer, G., Kaaijk, P., Ruiterkamp, N., Wijffels, R. H., van den Dobbelsteen, G. P. J. M., et al. (2013a). Improved production process for native outer membrane vesicle vaccine against Neisseria meningitidis. PLoS One 8:e65157. doi: 10.1371/journal.pone.0065157

van de Waterbeemd, B., Zomer, G., van Den Ijssel, J., van Keulen, L., Eppink, M. H., van Der Ley, P., et al. (2013b). Cysteine depletion causes oxidative stress and triggers outer membrane vesicle release by Neisseria meningitidis; implications for vaccine development. PLoS One 8:e54314. doi: 10.1371/journal.pone.0054314 van Der Ley, P., Steeghs, L., Hamstra, H. J., Ten Hove, J., Zomer, B., and van Alphen, L. (2001). Modification of lipid a biosynthesis in Neisseria meningitidis lpxL mutants: influence on lipopolysaccharide structure, toxicity, and adjuvant activity. Infect. Immun. 69, 5981-5990. doi: 10.1128/IAI.69.10.5981-5990.2001

van der Pol, L., Stork, M., and van der Ley, P. (2015). Outer membrane vesicles as platform vaccine technology. Biotechnol. J. 10, 1689-1706. doi: 10.1002/ biot. 201400395

van Dijk, A., Van Eldik, M., Veldhuizen, E. J. A., Tjeerdsma-van Bokhoven, H. L. M., de Zoete, M. R., Bikker, F. J., et al. (2016). Immunomodulatory and anti-inflammatory activities of chicken cathelicidin-2 derived peptides. PLoS One 11:e0147919. doi: 10.1371/journal.pone.0147919

van Harten, R., van Woudenbergh, E., van Dijk, A., and Haagsman, H. (2018). Cathelicidins: immunomodulatory antimicrobials. Vaccine 6:63. doi: 10.3390/ vaccines 6030063

van Ulsen, P., Zinner, K. M., Jong, W. S. P., and Luirink, J. (2018). On display: autotransporter secretion and application. FEMS Microbiol. Lett. 365:165 doi: 10.1093/femsle/fny165

von Bergen, M., Steiniger, F., Baumgarten, T., Wick, L. Y., Heipieper, H. J., Seifert, J., et al. (2012). Membrane vesicle formation as a multiple-stress response mechanism enhances Pseudomonas putida DOT-T1E cell surface hydrophobicity and biofilm formation. Appl. Environ. Microbiol. 78, 6217-6224. doi: 10.1128/aem.01525-12

Wang, S., Gao, J., and Wang, Z. (2018). Outer membrane vesicles for vaccination and targeted drug delivery. Wiley Interdiscip. Rev. Nanomed. Nanobiotechnol. 11:e1523. doi: 10.1002/wnan.1523

WHO (2016). WHO World Health Organization: immunization, vaccines and biologicals. Vaccine preventable diseases Vaccines monitoring system 2016 Global Summary Reference Time Series: BCG. World Heal. Organ. Available at: http://apps.who.int/immunization_monitoring/globalsummary/timeseries/ tsincidencepertussis.html (Accessed March 20, 2020).

Wuerth, K. C., Falsafi, R., and Hancock, R. E. W. (2017). Synthetic host defense peptide IDR-1002 reduces inflammation in Pseudomonas aeruginosa lung infection. PLoS One 12:e0187565. doi: 10.1371/journal.pone.0187565

Yem, D. W., and Wu, H. C. (1978). Physiological characterization of an Escherichia coli mutant altered in the structure of murein lipoprotein. J. Bacteriol. 133, 1419-1426. doi: 10.1128/jb.133.3.1419-1426.1978

Yonezawa, H., Osaki, T., Kurata, S., Fukuda, M., Kawakami, H., Ochiai, K., et al. (2009). Outer membrane vesicles of Helicobacter pylori TK1402 are involved in biofilm formation. BMC Microbiol. 9:197. doi: 10.1186/1471-2180-9-197

Yoon, H. (2016). Bacterial outer membrane vesicles as a delivery system for virulence regulation. J. Microbiol. Biotechnol. 26, 1343-1347. doi: 10.4014/ jmb.1604.04080

Yun, S. H., Park, E. C., Lee, S. Y., Lee, H., Choi, C. W., Yi, Y. S., et al. (2018). Antibiotic treatment modulates protein components of cytotoxic outer membrane vesicles of multidrug-resistant clinical strain, Acinetobacter baumannii DU202. Clin. Proteomics 15:28. doi: 10.1186/s12014-018-9204-2

Zanetti, M. (2004). Cathelicidins, multifunctional peptides of the innate immunity. J. Leukoc. Biol. 75, 39-48. doi: 10.1189/jlb.0403147

Zasloff, M. (2002). Antimicrobial peptides of multicellular organisms. Nature 415, 389-395. doi: 10.1038/415389a

Zhou, L., Srisatjaluk, R., Justus, D., and Doyle, R. (1998). On the origin of membrane vesicles in Gram-negative bacteria. FEMS Microbiol. Lett. 163, 223-228. doi: 10.1111/j.1574-6968.1998.tb13049.x. PMID: 9673026

Zingl, F. G., Kohl, P., Cakar, F., Leitner, D. R., Mitterer, F., Bonnington, K. E., et al. (2020). Outer membrane vesiculation facilitates surface exchange and in vivo adaptation of Vibrio cholerae. Cell Host Microbe 27, 225.e8-237.e8. doi: $10.1016 /$ j.chom.2019.12.002

Conflict of Interest: The authors declare that the research was conducted in the absence of any commercial or financial relationships that could be construed as a potential conflict of interest.

Copyright (c) 2021 Balhuizen, Veldhuizen and Haagsman. This is an open-access article distributed under the terms of the Creative Commons Attribution License (CC BY). The use, distribution or reproduction in other forums is permitted, provided the original author(s) and the copyright owner(s) are credited and that the original publication in this journal is cited, in accordance with accepted academic practice. No use, distribution or reproduction is permitted which does not comply with these terms. 